\title{
Nutritional Status and Associated Factors Among Adult HIV/AIDS Patients Receiving ART in Dilla University Referral Hospital, Dilla, Southern Ethiopia
}

\author{
Mahlet Birhane ${ }^{1} \quad$ Eskindir Loha $^{2} \quad$ Fikadu Reta Alemayehu ${ }^{1}$ \\ 1.Academic Center of Excellence for Human Nutrition in Ethiopia, SNFST, Hawassa University \\ 2.College of Health Sciences, Hawassa University
}

\begin{abstract}
Without appropriate intervention, HIV/AIDS and Malnutrition are interconnected and can worsen health situation of individuals in a vicious cycle. In Sub Saharan African countries including Ethiopia, the problem of HIV/AIDS, poverty and malnutrition are among the top development concerns. However, little have been studied about nutritional status of HIV/AIDS patients receiving ART drugs. Thus, in this study we did assess nutritional status of adults living with HIV/AIDS receiving ART in Dilla University Referral Hospital, Gedio zone, Southern Ethiopia. Institutional-based cross-sectional study was used from March to May 2015 on 389 PLWHA adults taking ART drug at the hospital. Study participants were randomly selected among all adult ART clients at the Hospital. Data collection was done using: face-to-face interview using structured and pretested questionnaire, secondary data from the record in the hospital and Anthropometric measurement. Data analysis was done using SPSS and Microsoft Excel. There was $100 \%$ response rate and majority (about $60 \%$ ) of the study participants were female where as $25 \%$ of them had chronic energy deficiency with $\left(\mathrm{BMI}<18.5 \mathrm{~kg} / \mathrm{m}^{2}\right)$. Among key factors that predict nutritional status of the study participants were: Clinical stage of HVI/AIDS infection, wealth status, presence of care giver, dietary diversity, food security status and CD4 cell count were significantly associated with under nutrition. In addition to clinical factors, food insecurity and low dietary diversity status were found as important risk factor associated with malnutrition. We concluded that, since only ART can't solve problem of malnutrition, attention needs to be given to improve income, food security, feeding habits and dietary diversity of PLWHA.
\end{abstract}

Keywords: Nutritional status, HIV/AIDS, ART, Dilla University Referral Hospital

DOI: $10.7176 / \mathrm{JMPB} / 70-02$

Publication date: April $30^{\text {th }} 2021$

\section{Background}

Approximately 37 million people in the world are currently living with HIV/AIDS (USAIDS, 2014). Currently, about 2 million people were newly infected and over 1.2 million people died of HIV/AIDS (UNAIDS, 2014). Africa has the highest HIV prevalence rates in the world. Sub-Saharan Africa (SSA) remains the worst hit region with AIDS (World Health Statistics, 2008). In 2014, an estimated 1.4 million people in the region became newly infected (UNAID 2014). The majority (90\%) of adults newly infected with HIV are in the Sub-Saharan Africa (SSA) (UNAIDS and UNICEF, 2012).

Ethiopia is one of the countries hit hardest by HIV epidemic alongside of malnutrition and it occurs in severe forms and affects many people either before or within the era of ART (IBR and World Bank, 2007). Latest report by WHO indicated that there are nearly 1.2 million people living with HIV/AIDS where as the adult prevalence rate is estimated at $2.4 \%$ and the incidence rate is $0.29 \%$ in Ethiopia (WHO, 2017). The responses to the HIV/AIDS epidemic showed considerable progress and achieved encouraging results. However, the nature of the epidemic and its fuelling factors creates a complex challenge to the ability of health and other sectors to meet the targets for HIV/AIDS control in Ethiopia (WHO, 2017). Antiretroviral treatment coverage reached $62.3 \%$, which is above the sub-Saharan African regional average $(53 \%)$. However, prevention of mother-to-child transmission of HIV coverage was only 9.3\% (WHO, 2017). In addition, The HIV/AIDS epidemic continues its impact on health, nutrition, food security and overall socioeconomic development of the population affected by the disease. HIV and nutrition are closely related to each other. Immune deficiency as a result of HIV infection leads to malnutrition which in turn, leads to immune deficiency, worsening the effect of HIV and contributing to the more rapid progression to AIDS (FANTA, 2003). Good nutrition, on the other hand, gives strength, helps to maintain and improve performance of the immune system thereby protecting the body against infection and delaying progression of the disease (Pal et al., 2012). The interaction of HIV/AIDS with nutritional status has been a distinguishing characteristic of the disease course since the earliest day of the epidemic. The term "slim disease" was often used in epidemic area such as Sub-Saharan African countries to reflect the wasting syndrome characteristically associated with HIV/AIDS and related disease (Serwadda et al., 1985; Keou, 1992). People with HIV/AIDS often do not eat enough because the illness and the medicines taken for it reduce the appetite, modify the taste of food and prevent the body from absorbing it. The symptoms such as 
a sore mouth, nausea and vomiting make it difficult to eat. Tiredness, isolation and depression reduce the appetite and the willingness to make an effort to prepare food and eat regularly (Tsitsi and Kurebwa, 2014). For people living with HIV (PLWHA), poor nutrition worsens the effects of HIV by further weakening the immune system. This may lead to a more rapid progression of the disease. Moreover, HIV interferes with the ability to access, handle, prepare, eat and utilize food, thus increasing the risk of malnutrition among people living with HIV (Mhiri C., 1992).A well-nourished person with HIV who has a controlled viral load is more likely to be able to withstand the effects of HIV infection, supporting immune status and possibly delaying the progression of HIV disease (WFP, 2005). The negative effects of malnutrition are often preventable but are usually not easily reversed. Nutrition-related alterations occur early in HIV infection. Nutritional care and support must be started at the early stages of the infection, ideally soon after diagnosis (Pal et al., 2012).Maintaining adequate food consumption and nutrient intake levels and meeting the special nutritional needs to cope up with the disease and the ART are critical for PLWHA to achieve the full benefit of such a treatment (wheeler et al., 1999). In resource limited settings, many PLWHA lack access to sufficient quantities of nutritious foods, which poses additional challenges to the success of Anti Retroviral Therapy (ART) (Castle man et al., 2004 and World Bank 2009).

HIV/AIDS and malnutrition effects are interrelated and exacerbate one another in a vicious cycle. HIV specifically affects nutritional status by increasing energy requirements, reducing food intake, and adversely affecting nutrient absorption and metabolism. Asymptomatic and symptomatic adults have increased energy requirements by $10 \%$ and $30 \%$ respectively to maintain body weight and physical activity (Stephen D., 2008, Daniel et al., 2005, Bonnard et al., 2006). Even if lots of efforts have been done to minimize prevalence of HIV/AIDS in Ethiopia, there is limited evidence about nutrition related intervention and nutritional status of people living with HIV/AIDS especially those taking ART drugs. Yet, good nutrition is expected to promote effectiveness of ART drugs and minimize progression of HIV in the body of patients. Thus, the major objective of this study was to assess nutritional status of adult HIV/AIDS patients taking ART and associated factors in Dilla University Referral Hospital, Gedio zone, Southern Ethiopia so that the finding can support future studies and interventions.

METHODS AND MATERIALS: Study design and study area: Facility based cross sectional study design at Dilla University Referral Hospital was conducted from February to March 2015. Dilla University referral Hospital is found in Dilla City administration which is located 360 kilometers away from the capital city, Addis Ababa, in the South of Ethiopia. It is a public hospital which is an affiliate of Dilla University providing training for health sciences student in a range of disciplines. Additionally, the hospital provides higher level of clinical care for nearly a million of catchment area populations. Since 2005, the Hospital has been providing highly active antiretroviral therapy (HAART) for PLWHAs. During this time there were a total of 3310 PLWHA on chronic HIV care and 1556 are on ART treatment (HAART). Of these, 49 are under 18 years old while 1507 are above. According to the national guideline, ART should be initiated for eligible patient. The eligibility of the patients is determined either if their CD4 cell count is $<500$ cells $/ \mathrm{mm}^{3}$ or if they fulfill WHO clinical AIDS stage III or IV (WHO, 2014). Dilla University referral Hospital is purposively selected for this study since there is limited report about nutritional status and feeding practice of PLWHAs who are attending ART services.

Subjects and sampling:The source populations for this study were all PLWHA in Dilla town and the surrounding area that were enrolled for ART follow-up service at Dilla University Referral Hospital. The study populations were people with the age of 18 years and above who were actively receiving ART and volunteer to participate in the study. The study participants were selected randomly using a computer generated simple random number based on patient ART unique identification number. Each patient was recruited (studied) only once, on his/ her first visit during the study period, if selected. Repeated visits were excluded by recording registration numbers of each client at the time of interview and checking thereafter for avoidance of possible repetition. Random selection of participants was done prior to patients presenting to clinic. A total of 398 individuals participated in the study calculated based on single population proportion formula: $\mathrm{p}=12.3 \%$ (proportion of under nutrition among adult HIV positive individuals in the study area (Solomon et al., 2013) $\mathrm{z}=$ 1.96 and $\mathrm{d}=3 \%$ because estimated prevalence was $<15 \%$. So, to increase the sample size, $\mathrm{d}$ (margin of error) should be less than 5\%. Patients who were already attending ART and aged 18 years and older were included in the study. However, pregnant women, lactating mothers (6 months of postpartum) and those who were seriously ill were excluded from the study.

Data collection: The data was collected from primary and secondary data sources. The primary quantitative data was collected from the sample respondents using a pre-tested, semi-structured questionnaire and weight and height of the subjects was done using height measuring board and weight measuring scales. The survey questionnaire was translated first from English into Amharic, and then retranslated back to English by an expert to maintain its consistency. Data collectors were fluent both the Amharic and the local language (Gediofa). Data collectors were given a two days training on data collection prior to the start if data collection. Data on past or present opportunistic disease, WHO clinical stages of disease and chronic diseases was obtained from patient 
charts and ART follow-up forms. CD4 T cell count was also obtained from the chart as the investigation was done on routine basis. The data collection process was followed daily by the supervisor and principal investigators. Weight of participant's was taken using standard beam balance and the scale was calibrated at zero before and after each measurement. Participants' weight was measured after removing heavy clothes and recorded to the nearest $0.1 \mathrm{Kg}$. Height was measured using the standard scale. The subjects were asked to remove their shoes, stood erect, and positioned at the Frankfurt plane with feet together and knees straight. The heels, buttocks, shoulder blades and the back of the head (occiput) were in touch against the vertical stand of the stadio meter and the values were recorded to the nearest $0.1 \mathrm{~cm}$

Socio economic status and Diet Diversity status: Questions about monthly income, family size, marital status etc were used to assess socio-economic status where as Dietary diversity was assessed using the questions specifically about food consumption during the past $24 \mathrm{hr}$ period containing Cereals, Oils/Fat, vitamin A rich fruits and vegetables, Legumes, Root/Tubers, dark green leafy Vegetables, flesh Meat including fish, organ meat, Milk/Milk products, Eggs and foods that are commonly consumed in the study area. Participants were asked to report/write down all the foods or drinks including the raw material used to prepare the food. All foods eaten by the individual of interest, consumed inside or outside the home, irrespective of where they were prepared were also reported by the study participants. Participants received 1 point if they consumed at least once during the last 24 hours of the foods within each subgroup and 0 points if they never consumed the food. The food items were grouped into nine according to FAO guide line for measuring individual and household dietary diversity (FAO, 2011). A Dietary Diversity Score (DDS) was calculated as the sum of the food groups consumed over 24 hours. The dietary diversity score ranged from one to nine. Diet Diversity was reported as highest when more than 6 food groups reported and medium when 4 to 5 food groups reported and low when less than or equal to three food groups reported.

House hold food security status: There were a total of 18 questions specifically prepared to assess food security status of the study participant which was adapted from FANTA version 3. Each of the questions was asked with a recall period in the last four weeks (30 days) before the survey. Responses were tallied for occurrence and frequency of occurrence which produced a score for each household. This score is classified into one of four categories: food secure, mildly food insecure, moderately food insecure and severely food insecure (FANTA, 2007).

Data Analysis: After completing the data collection processes, the data was coded, edited and entered into the statistical package SPSS version 17 and analyzed using descriptive statistics, Household food security status and dietary Diversity Score and principal component analysis (PCA). Descriptive and Inferential statistics: Categorical type of data was analyzed using percentage, frequency, distribution and ANOVA, While quantitative continuous types of variables was analyzed using minimum, maximum, mean and standard deviation. Binary and multiple logistic regression models were applied to estimate the effects of explanatory variables on respondent nutritional status.

Ethical considerations: In order to proceed to data collection, permission was obtained from the Hawassa University IRB. Objectives of the study were told and written consent was obtained from each respondent before proceeding to the interview. Seriously ill and malnourished patients during the study were recommended to the hospital to be transferred to the inpatient unit for further treatment. At the end of the interview each and every client was get nutrition counseling.

\section{RESULTS}

In this study, a total of 389 patients on ART were included with $100 \%$ response rate. More than half (60.4\%) of the study participants were female. The mean (SD) age of the study group was 39.72( \pm 9.54$)$ years. The largest numbers of the clients $235(60.4 \%)$ were adults in the age range of 30-44 years of age. Over half $(60.2 \%)$ of the participants were orthodox by religion and $276(71 \%)$ were married. From the total of respondents, 150(38.6\%) can only read and write while, only $62(15.9 \%)$ got secondary education and above. Mean family size of the study participants was 4.74 with SD of 2.2. Majority 371(95.1\%) of the study participants were urban resident. From the total respondents, majority 353 (90.7) patients had no social discrimination at working place, home or in the community and $199(51.2 \%)$ had care giver at home. Wealth status of the respondents range from richest to poorest almost evenly distributed among each wealth class from poorest to richest. Majority of the respondents $(88.7 \%)$ were employed at the time of data collection. In addition, $62.2 \%$ of the study participants were food insecure, of which $21.3 \%$ were mildly food insecure, $26 \%$ were moderately food insecure and $14.9 \%$ were severely food insecure. Among $98(25.2 \%)$ malnourished individuals $55(56.1 \%)$ were adults in the age group of $30-44$ years old, $63(64.3 \%)$ female and $35(37.7 \%)$ male were malnourished.

Disease stages of the respondents: About a third of the respondents $(32.4 \%)$ in WHO clinical stage III while WHO clinical stage IV 99(25.4\%) was the second. According to patient medical chart report, one hundred four patients $(26.7 \%)$ currently had opportunistic infection, of which 65 patients $(62.5 \%)$ had tuberculosis infection and accounted for the uppermost co-infection. Sixty $(15.4 \%)$ had eating problem and over half $(51.4 \%)$ of 
patients were treated for more than thirsty six months of duration while only $25(6.4 \%)$ were treated for six to eleven months. Mean (SD) CD4+T cell count of patients' were $473 \pm 244.17$. The minimum CD4+ T cell count was $31 \mathrm{cell} / \mathrm{mm}^{3}$ while 1547 cells $/ \mathrm{mm}^{3}$ was the maximum. Table 4-3 presents medical characteristics of the study participants. In addition, Mean CD4 T-cell count of female is a little bit lower than male $(470 \pm 248.6 \mathrm{Vs}$ $479 \pm 237.8)$ respectively. But this was not a significant difference $(p>0.05)$. There was also not a significant difference in mean BMI among different age groups of study participants $(p>0.05)$.

Dietary diversity status of the study participant: Dietary diversity score of study participants was obtained using 24 hour recall, calculated and divided into 3 categories based on FAO guide line for measuring individual and household dietary diversity (FAO, 2011).The mean (standard deviation) for dietary diversity score of the previous $24 \mathrm{hr}$ was $4.51 \pm 1.42$. One hundred eighty six $(47.8 \%)$ of study participants had medium dietary diversity status (4-5 food groups) while $84(21.6 \%$ ) had low dietary diversity score ( $\leq 3)$ food groups. Cereals 383 $(98.5 \%)$ and other fruits and vegetables $325(83.5 \%)$ were the most food group which were consumed by almost all of the study participants while organ meat $33(8.5 \%)$ were the least.

Diet diversity status of study participants $(\mathrm{N}=389)$

\begin{tabular}{|ccc|}
\hline Dietary diversity status & Number & $\%$ \\
\hline High dietary diversity score (>6) food groups & 119 & 30.6 \\
Medium dietary diversity score (4-6) food groups & 186 & 47.6 \\
Low dietary diversity score ( $\leq 3$ 3) food groups & 84 & 21.6 \\
Mean(SD) of dietary diversity score 4.51 $\mathbf{1 . 4}$ & & \\
\hline
\end{tabular}

Nutritional Status of the subjects

The overall prevalence of under nutrition (BMI $<18.5 \mathrm{~kg} / \mathrm{m}^{2}$ ) among PLWHA receiving ART in Dilla University referral Hospital was $25.2 \%$. In addition, $73(18.8 \%)$ patients were mildly, 13(3.3\%) moderately malnourished and $12(3.1 \%)$ were severely malnourished. In this study prevalence of overweight and obesity was $3.6 \%$ and $0.8 \%$ respectively. One hundred ninety nine $(51.2 \%)$ patients received nutritional counseling from ART nurses or adherence support group. From those, only $34(17.0 \%)$ were undernourished. From a total of 98 $(25.2 \%)$ undernourished patients, $65.3 \%$ didn't received nutritional counseling. Two hundred sixty nine (69.2\%) didn't have nutritional support, out of them $57.1 \%$ were under weight.

\section{Factors associated with nutritional status of the respondents}

In this study, both the bivariate and multivariate logistic regression analysis was computed. Out of Ten (10) variables that showed significant association with under nutrition in the bivariate analysis, Five (Dietary diversity status, wealth quintiles, CD4 cell count, presence of care giver, WHO clinical stage and House hold food security access scale) were significantly associated with under nutrition when data were entered into the multivariate analysis. Four variables that showed significant association on the bivariate model (Presence of opportunistic infection, nutritional support, nutritional counseling and presence of eating problem) had no further statistical significant association with under nutrition on the multivariate logistic regression model.

Being in the middle and the fourth wealth quintiles were significantly associated with under nutrition as compared with the first wealth quintile. Patients who were in the middle wealth quintile were reduced the odds of under nutrition by $74 \%$ ( $\mathrm{AOR}=0.26 ; 95 \% \mathrm{CI} 0.09-0.74)$ while the fourth wealth quintile reduce the odds of under nutrition by $77 \%(\mathrm{AOR}=0.23 ; 95 \% \mathrm{CI} 0.08-0.66)$. WHO clinical stage was also significantly associated with under nutrition. Being in WHO clinical stage IV was increase the odds of under nutrition by 2.56 times $(\mathrm{AOR}=2.56 ; 95 \% \mathrm{CI} 1.04-6.26)$.CD4 cell count also had statistically significant association with under nutrition. Patients who had moderate CD4 count $\left(200-350 \mathrm{cell} / \mathrm{mm}^{3}\right)$ and sever CD4 count $\left(<200 \mathrm{cell} / \mathrm{mm}^{3}\right)$ was increase the odds of under nutrition by 2.69 times $(\mathrm{AOR}=2.69 ; 95 \% \mathrm{CI} 1.07-6.77)$ and 2.95 times $(\mathrm{AOR}=2.95 ; 95 \% \mathrm{CI} 1.04-$ $8.39)$ respectively as compared with patients having normal CD4 cell count $\left(>500 \mathrm{cll} / \mathrm{mm}^{3}\right)$. Presence of care giver also had statistically significant association with under nutrition. Patients with care giver were reduced the odds of under nutrition by $92 \%(\mathrm{AOR}=0.08$; 95\%CI $0.03-0.17)$. Dietary diversity and household food security status had statistically significant association with under nutrition in both the bivariate and multiple logistic regression models. Patients who were severely food insecure were 2.82 times more likely to be undernourished as compared to those patients who were food secure $(\mathrm{AOR}=2.82 ; 95 \% \mathrm{CI} 1.12-7.13)$.In addition to this, having inadequately diversified diet were increased the odds of under nutrition by 4.55 times $(\mathrm{AOR}=4.55$; $95 \% \mathrm{CI} 2.23$ 9.29). 
Table 1. Factors predicting Nutritional status of the study participants

\begin{tabular}{|c|c|c|c|c|}
\hline Variables & Underweight & Normal & COR(95\%CI) & $\operatorname{AOR}(95 \% C I)$ \\
\hline Wealth quintiles & No (\%) & No (\%) & & \\
\hline Poorest & $4 \overline{5}(45.9)$ & $39(13.4)$ & $1^{\mathrm{r}}$ & $1^{\mathrm{r}}$ \\
\hline Second & $21(21.4)$ & $57(19.6)$ & $0.32(0.17-0.62)^{*}$ & $0.49(0.19-1.27)$ \\
\hline Middle & $11(11.2)$ & $66(22.7)$ & $0.14(0.07-0.31)^{*}$ & $0.26(0.09-0.74)^{*}$ \\
\hline Fourth & $11(11.2)$ & $67(23)$ & $0.14(0.07-0.31)^{*}$ & $0.23(0.08-0.66)^{*}$ \\
\hline Highest & $10(10.2)$ & $62(21.3)$ & $0.14(0.06-0.31)^{*}$ & $0.43(0.15-1.29)$ \\
\hline Total & $98(100)$ & $291(100)$ & & \\
\hline \multicolumn{5}{|c|}{ Presence of care giver } \\
\hline No & $87(88.8)$ & $103(35.4)$ & $1^{\mathrm{r}}$ & $1^{\mathrm{r}}$ \\
\hline Yes & $11(11.2)$ & $188(64.6)$ & $0.07(0.04-0.14)^{*}$ & $0.08(0.03-0.17)^{* *}$ \\
\hline Total & $98(100)$ & $291(100)$ & & \\
\hline \multicolumn{5}{|c|}{ WHO stage of AIDS } \\
\hline Stage I & $15(15.3)$ & $73(25.1)$ & $1^{\mathrm{r}}$ & $1^{\mathrm{r}}$ \\
\hline Stage II & $15(15.3)$ & $61(21)$ & $1.19(0.54-2.64)$ & $1.62(0.55-4.77)$ \\
\hline Stage III & $25(25.5)$ & $101(34.7)$ & $1.25(0.72-2.88)$ & $1.02(0.39-2.60)$ \\
\hline Stage IV & $43(43.9)$ & $56(19.2)$ & $3.74(1.89-7.39)^{*}$ & $2.56(1.04-6.26)^{*}$ \\
\hline Total & $98(100)$ & $291(100)$ & & \\
\hline \multicolumn{5}{|l|}{ Presence of OIs } \\
\hline No & $56(57.1)$ & $229(78.7)$ & $1^{\mathrm{r}}$ & $1^{\mathrm{r}}$ \\
\hline Yes & $42(42.9)$ & $62(21.3)$ & $3.14(1.92-5.12)^{*}$ & $1.75(0.84-3.67)$ \\
\hline Total & $98(100)$ & $291(100)$ & & \\
\hline \multicolumn{5}{|c|}{ Nutritional counseling } \\
\hline No & $64(65.3)$ & $126(43.3)$ & $1^{\mathrm{r}}$ & $1^{\mathrm{r}}$ \\
\hline Yes & $34(34.7$ & $165(56.7)$ & $0.43(0.27-0.69)^{*}$ & $1.51(0.74-3.07)$ \\
\hline Total & $98(100)$ & $291(100$ & & \\
\hline \multicolumn{5}{|c|}{ Nutritional support } \\
\hline No & $58(59.2)$ & $211(72.5)$ & $1^{\mathrm{r}}$ & $1^{\mathrm{r}}$ \\
\hline Yes & $40(40.8)$ & $80(27.5)$ & $2.05(1.27-3.29)^{*}$ & $0.59(0.28-1.26)$ \\
\hline Total & $98(100)$ & $291(100)$ & & \\
\hline
\end{tabular}

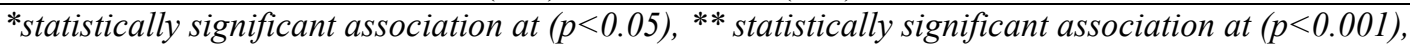

$C O R=$ crude odds ratio, $A O R=$ adjusted odds ratio, $1^{r}$ reference.

Source: Field survey data

\section{Discussions}

In this study, there were more female cases than male. This might be due to the high prevalence of HIV/AIDS infection among females than males (CSA, 2011). More urban residences were also participated than rural counterpart which could be attributed to the higher proportion of urban with HIV infection as seen in the DHS 2011 which was $4.2 \%$ for urban and $0.6 \%$ rural residences (CSA, 2011). Mean family size of the study participant was $4.74 \pm 2.20$ which is almost similar to the national mean family size (4.9). The mean BMI of female $\left(20.5 \mathrm{~kg} / \mathrm{m}^{2}\right)$ and male $\left(19.9 \mathrm{~kg} / \mathrm{m}^{2}\right)$ were almost similar with the mean BMI of the general Ethiopian women population $20 \mathrm{~kg} / \mathrm{m}^{2}$ and the general Ethiopian male population $19 \mathrm{~kg} / \mathrm{m}^{2}$, respectively $(\mathrm{CSA}, 2011)$.

\section{Factors affecting nutritional status of PLWHA}

Socio-economic factors have an effect on nutritional status of people living with HIV/AIDS (PLWHA) receiving ART. Many studies indicate that wealth status of study participants had direct relationship with under nutrition. In this study, being in the middle and fourth wealth quintiles reduces the odds of under-nutrition by $74 \%$ and $77 \%$ as compared to that of the study participants who were in the lowest wealth quintile (AOR $=0.26,95 \% \mathrm{CI}$ 0.09-0.74) and AOR=0.23 95\% CI 0.08-0.65), respectively. This is consistent with a research done in Gondar University referral hospital which revealed that poor economic status as risk factor to develop under nutrition as compared to that of the rich (Belayneh et al., 2010). Solomon et al. also reported that, medium economic status reduce the odds of under nutrition by $60 \%(\mathrm{AOR}=0.4095 \% \mathrm{CI} 0.14-0.95)$.

CD4-T cell count had strong positive correlation with BMI of study participants, which indicates that when CD4 $\mathrm{T}$ cell count increases, BMI will be also increase and the reverse is true. This result is consistent with similar study conducted in Boston explained that improved CD4 cell counts help to reduce the incidence of opportunistic infections and this in turn reduces the occurrence of under nutrition. The Boston study also found that, each $100 \mathrm{cell} / \mathrm{mm}^{3}$ decrease in CD4 count is associated with a $1.9 \mathrm{~kg}$ decrease in body weight (Mangili et al., 2006). 
In the current study, prevalence of house hold food insecurity is $62.2 \%$. This result is consistence with a study done in Jimma University Referral Hospital on 319 PLWHA which was 63 \% (Ayele et al., 2012). But this result is lower than similar study conducted in Hosanna health care settings which indicate that overall prevalence of food insecurity were $68 \%$ ( Mekuria et al., 2015). This might be due to the difference in socioeconomic characteristics of the study participants. In another study, the proportion of mild, moderate and severe food insecurity was 4.6\%, 32.5\% and 42\% respectively (Dereje et al., 2015,). Asnakew et al., 2015 also found that the degree of food insecurity was $76.5 \%, 17.5 \%$ and $5.8 \%$ occurred as in mild, moderate and severe form.

In the current study, food insecurity has significant association with under nutrition. Being severely food in secure increased the risk of under nutrition by 2.82 times ( $\mathrm{AOR}=2.82$ 95\%CI 1.12-7.13). This might be because of the fact that food insecure study subjects might based their diets on less nutritious and cheap foods or eat one types of meal for long periods of time or even they stay the whole day without food due to lack of money to purchase. This is evidenced by a study done in Jimma university specialized hospital, which revealed that increasing food insecurity status in the study group were associated with reducing food diversity status (Ayele et al., 2012). Similar study conducted in Humera hospital Northern Ethiopia also found that significant association between under nutrition and food security status of PLWHA ( $\mathrm{p}=0.001)$. According to this author, respondents with household food insecurity were 1.9 times more likely to have significant weight loss as compared to those who were food secure $(\mathrm{AOR}=1.90 ; 95 \% \mathrm{CI}$ : 1.11-3.25) (Tsegazeab et al., 2013). Another study conducted in Malawi also found that food insecurity is an important contributing factor to the development of wasting in PLWHA (Bahwere et al.,2011). A study in Hosanna health care settings reported that, being food insecure increased the odds of under nutrition by 2.51 (AOR=2.51;95\%CI 1.31, 4.81)(Mekuria et al.,2015).

WHO clinical stage IV of AIDS has significant association with under nutrition. Patients who were in WHO clinical stage IV of AIDS increase the odds of under nutrition by 2.56 times (95\%CI 1.04-6.26) as compared to that of patients in WHO clinical stage I. This study is also supported by the same study done in Hosanna town health care settings. Patients who were WHO clinical stage IV were 5.23 times more likely to be malnourished (Mekuria et al., 2015). Similarly, a study done in Uganda shows that PLWHA taking ART at WHO clinical stage IV were characterized by sever wasting, chronic fever, chronic diarrhea and weight loss greater than $10 \%$ from baseline and weight gain was observed among individuals with less advanced disease (Rawat et al., 2010). This is due to the fact that malnutrition is usually encountered at the advanced phase or end of the HIV infection course(WHO,2005). According to our study, there was not statistically significant association in getting nutritional support and nutritional status of study participants even though $56(57.1 \%)$ of undernourished individuals were from $269(69.2 \%)$ of subjects who didn't get nutritional support. This finding was opposite with a study done in Zambia which was found that Interventions using supplements or food at time of ART commencement may improve treatment outcomes and providing food support to food insecure patients increased ART adherence by $40 \%$ and increased weight during the first 6 months of treatment (Megazzini KS.et al., 2006). Similarly, a study done in Uganda found that PLWHA receiving food assistance at baseline WHO stage II and III had a significant weight gain $(0.26 \mathrm{~kg}$ and $0.2 \mathrm{~kg}$ respectively) as compared to their matched controls with the same baseline WHO stage who did not received food assistance. Those with the most advanced disease stage at baseline (WHO stage IV) had the highest weight gain point estimate over the one year period $(1.9 \mathrm{~kg})$ (Rawat et $a l$. , 2010).This difference in our study might be due to the difference in study design.

In the current study, mean standard deviation of dietary diversity score was $4.51 \pm 1.42$. This score is a little bit lower than a study done in Uganda, Kampala (4.99 \pm 1.37 ) (carol, 2004). This might be due to the small sample size in the Uganda study (169) as compared to the current study and or the difference in socio-economic and cultural characteristics of the study participants. Diet diversity result also indicates that majority of study participants $186(47.8 \%)$ have moderate dietary diversity score. Eighty four (21.6\%) respondents had low dietary diversity status which was much lower than a study done in hosanna health care settings in which larger proportion of the respondents $(67.9 \%)$ had inadequately diversified food(Mekuria et al.,2015). This might be due to the difference in socio economic status of study participants. Cereals and fruits and vegetables were the most food groups which were consumed by the study participants $(98.5 \%$ and $83.5 \%)$ respectively which were good. Similar study conducted in jimma also supports this finding which was found that $98.1 \%$ and $62.7 \%$ of cereals and vegetables were consumed by the study subjects (Ayele et al., 2012). Our study found that consumption of cereals which are generally cheaper was higher than animal products such as organ meat, egg and fish (98.5\%vs $8.5 \%$ and $17.7 \%$ respectively. This might be due to that most clients were food insecure and was normally eat a staple and cereals at main meals which are relatively cheaper than animal products.

In the current study, malnutrition $\left(\mathrm{BMI}<18.45 \mathrm{~kg} / \mathrm{m}^{2}\right)$ was significantly associated with dietary diversity status. Patients having inadequate dietary intake were increase the odds of under nutrition by 4.55 times $(\mathrm{AOR}=4.55 ; 95 \% \mathrm{CI} 2.23-9.29)$. This result was in line with the same cross-sectional study done in hosanna health care settings which was founded that, a positive relationship between under nutrition and dietary diversity status (Mekuria et al., 2015). This author explained that, clients who were taking adequate diversified food were $56 \%$ less likely to be malnourished than those who have inadequate diversified food ( $\mathrm{AOR}=0.44,95 \% \mathrm{CI}: 0.23$ 
- 0.84) .Tsegazeab et al. also supports this finding. As Tsegazeab and his colleagues finding, patients having inadequate dietary diversity were 2.83 times more likely to be undernourished as compared with their counterparts.

\section{Nutritional status of study participants}

In the current study, prevalence of under nutrition (BMI $\left.<18.5 \mathrm{~kg} / \mathrm{m}^{2}\right)$ was $25.2 \%$. This prevalence is much higher in similar study done in Dilla university referral hospital which was $12.3 \%$ ( Solomon et al., 2013).This high prevalence of malnutrition in the current study might be firstly, due to the year of study and secondly, this high rate of under nutrition in this study could be due to high prevalence of household food insecurity (62.2\%) leading to lack of access to adequate, safe and nutritious food resulting to under nutrition. Another research conducted in Ghana report that, prevalence of under nutrition $\left(\mathrm{BMI}<18.5 \mathrm{~kg} / \mathrm{m}^{2}\right)$ was $7.9 \%$ ( Theodosia et al., 2014) .The first reason for this small prevalence in Ghana might be due to the small sample size they use (63).The Second reason might be due to the characteristics of study participants. In the Ghana study, participants were those groups of patients who were not eligible for ART whose CD4 cell counts were $>=300 \mathrm{cell} / \mathrm{mm}^{3}$ or they are only from stage I and II. Exclusion of advance stages of AIDS might be undermine the prevalence of under nutrition since stage of AIDS increase, immunity of patients will decrease and prone patients to many opportunistic infection. This might cause reduce dietary intake, reduce nutrient metabolism and absorption and finally expose patients to malnutrition (Carole, 2004) and malnutrition is usually encountered at the advanced phase or end of the HIV infection course (WHO, 2005).

Malnutrition could occur in different forms and degrees. When considering degrees of malnutrition, it varies in different settings and circumstances. In the current study, from the total $25.2 \%$ of undernourished patients, $16.7 \%, 5.7 \%$ and $2.8 \%$ were in mild, moderate and sever under nutrition respectively. In another study Molla et al. and Dereje et al., it was $64.4 \%, 19.2 \%$, and $16.4 \%$ and $16.1 \%, 6.2 \%$, and 3.0\% respectively. Zecharia et al., in Malawi also report those different degrees of malnutrition as $22 \%$ mild, $14 \%$ moderate and $21 \%$ severe malnutrition was occurred among PLWHA.

Conclusion: Based on the finding of this study, household food insecurity was high (62.2\%) among PLWHA. In addition, $25 \%$ of the subjects had chronic energy deficiency which will aggravate their health status. Thus, further work is recommended in relation to improving dietary practices of PLWHA in the area.

Acknowledgement: The Authors would like to acknowledge the ENGINE/USAID Hawassa University project for funding this study

\section{References}

Ayele Tiyou, Tefera Belachew, FisehayeAlemsege and Sibhatu Biadglgn. 2012. Food insecurity and associated factors among HIV-infected individuals receiving highly active antiretroviral therapy in Jimma zone Southwest Ethiopia. Nutrition Journal.11:51.

Belayneh wasie, Yigzaw Kebede and Anwar Yibrie.2010. Nutritional status of adult living with HIV/AIDS in Gondar University referral Hospital. Ethiopian Journal of health. Bio medical science.3 (1)

Bonnard Tony c.,Bruce C.,Leslie E.,Sandra R.and Caroline.2006.Nutrition and HIV/AIDS: Evidence, Gaps and Priority action for academy for educational Development (AED),prepared by Eillnpiwoz of the support for analysis and research in Africa (SARA) project with input from Patricia.

Carol N.2004. Factors Associated With Dietary Intake among Hiv Positive Adults (18-65 Years) At The Mildmay Center, Kampala, Uganda.

Castle man T., Seumo-Fosso E.and Cogill B. 2004.Food and nutrition implication of antiretroviral therapy in resource limited setting. Washington DC: Food and nutrition technical assistance Project (FANTA) Academy for educational Development. Report \#7 at http://www.fanta project.org/publications/tn7.shtml website (accessed May 2009)

Central Statistics Agency(CSA).2011.Addis Ababa Ethiopia, ICF international, Calverton ,Mary land and USA .March 2012 .Central statistic Agency and ICF international

Dereje Gedle, Baye Gelaw, Dagnachew Muluye and Molla Mesele.(2015).Prevalence of malnutrition and its associated factors among adult people living with HIV/AIDS receiving anti-retroviral therapy at Butajira Hospital, southern Ethiopia BMC Nutrition 2015, 1:5.

Food and Nutrition Technical Assistance (FANTA) Project. 2004. HIV/AIDS: A Guide for Nutritional Care and Support. $2^{\text {nd }}$ edition. Washington, DC: FHI 360

Mangili A. murman DH., Zampini AM and Wanke CA. 2002. Nutrition and HIV infection. (42):836-842.

Mangili A. murman DH. Zampini AM and Wanke CA.2006. Nutrition and HIV Infection: Review of Weight Loss and Wasting in the Era of Highly Active Antiretroviral Therapy from the Nutrition for Healthy Living Cohort. Nutrition and HIV/AIDS division of geographic medicine and infectious disease (CID) 2006:4 
Megazzini KS, Washington M, Sinkala M, Lawson-Marriot S, Stringer E, and Krebs.(2006). A pilot randomized trial of nutritional supplements in food insecure patients receiving antiretroviral therapy in Zambia. In: Sixteenth International AIDS Conference; 2006; Toronto, Canada; 2006.

Mekuria Asnakew, Chernet Hailu and Habtamu Jarso.2014. Malnutrition and Associated Factors among Adult Individuals Receiving Highly Active Antiretroviral Therapy in Health Facilities of Hosanna Town, Southern Ethiopia. Open Access Library Journal, 2: e1289.

Meskerem Alemayehu kenea,Sileshi Garoma and Habtamu Fekadu Gemede.2015 Assessment of Adult Nutritional Status and Associated Factors Among ART Users in Nekemet Referral Hospital and Health Center, East Wollega Zone, Ethiopia. Journal of Food and Nutrition Sciences 2015; 3(2): 55-62

Mhiri C. 1992. The 'Slime disease' in Africa patient with AIDS. Trans royal society for tropical medicine and hygien.86:303-306.

Serwadda D, Mugerwa RD, Sewankambo NK, Lwegaba A. and Carswell JW. (1985) .Slim disease: A new disease in Uganda and its association with HTLV-III infection. Lancet 2:849-852.

Solomon Hailemariam, Girma Tenkolu Bune and Henok Tadesse Ayele. 2013. Malnutrition: Prevalence and its associated factors in People living with HIV/AIDS. 71:13.

Stephen D. 2008.World AIDS day, the role of nutrition in living with HIV/AIDS 01.Dec, 2008, pp 12-15.

Theodosia A., Rose B., David B., Godfred E., Isaac B., Dominic D.and Christian B.2014. Body composition of adults living with HIV in two cities in Ghana Science Journal of Public Health 2014; 2(4): 361-366

Tsegazeab Hailu Hadgu, Walelegn Worku ,Desalegn Tetemke ,Hailemariam Berhe (2013).

Undernutrition among HIV positive women in Humera hospital, Tigray, Ethiopia, 2013: antiretroviral therapy alone is not enough, cross sectional study, 13:94

Tsitsi P. and Dr Kurebwa Mercy. 2014. A Choice to Remain Healthy: An Analysis of Diet and Nutrition of People Living With HIV/AIDS. Sch. Acad. J. Biosci., 2(7): 410-418 ISSN 2347-9515).

UNAIDS (joint united nation program on HIV/AIDS). (2008).Global report on the global AIDS epidemic.ISBN 978-92-9253-032-7 (Nlm classification;wc 503.6.

UNAIDS and UNICEF. (2012). Enhancing Social Protection for HIV Prevention, Treatment, Care \& Support. The State of the Evidence. UNICEF/NYHQ2009 1912/Pirozzi.

UNAIDS Report. (2014).How AIDS changed everything, 2015; UNAIDS 2014 Global Statistics. (Last updated July 2015)

Wheeler DA.,Gibert and Lavnet CA .1999. Weight loss as a predictor of survival and diseases progression in HIV infection; Jerry Beirn community program for clinical resource on AIDS .J acquire immune deific syndr Hum Retrovirol. 18:80-85.

World Bank .2013. HIV/AIDS, nutrition and food security: what we can do. A Synthesis of international guidance. World Bank, 2013.

World Food Programme. (2005). A manual: Measuring and Interpreting Malnutrition and Mortality. Rome.

WFP, WHO and UNAIDS.2008. HIV, food security and nutrition. Expanded version, May, 2008

World Health Organization (WHO).2003.Nutrient requirements for people living with HIV/AIDS: Report of technical consultation. Swizerland, Geneva.

World Health Organization (WHO) 2005. Interim WHO Clinical Staging of HIV/AIDS and HIV/AIDS Case Definitions for Surveillance African Region. WHO/HIV/2005.02

World Health Statistics (WHO) 2008. Available at http://www.who.int/research/en/. 